\title{
Urbanismo neoliberal y fragmentación urbana: el caso de Zaragoza (España) en los primeros quince años del siglo XXI
}

Severino Escolano-Utrilla. Universidad de Zaragoza, Zaragoza, España. Carlos López-Escolano. Universidad de Zaragoza, Zaragoza, España. Ángel Pueyo-Campos. Universidad de Zaragoza, Zaragoza, España.

RESUMEN | El crecimiento del espacio urbano de Zaragoza durante los primeros quince años del siglo Xxi se caracteriza por su fragmentación socioespacial a varias escalas, un rasgo significativo del urbanismo neoliberal. En esta ciudad se ha seguido un modelo que se compone por grandes fragmentos monofuncionales, no separados unos de otros, sino soldados al espacio urbano preexistente por las principales arterias de circulación; estas vías y otros obstáculos físicos o percibidos interrumpen la continuidad con el espacio consolidado, sobre todo para el movimiento de personas. No obstante este patrón permite la conexión de los nuevos espacios con el entorno urbano local, al mismo tiempo fomenta la segregación social e impulsa un modelo policéntrico basado en desplazamientos en automóvil privado.

PALABRAS CLAVE | fragmentación urbana, planificación urbana, periferia urbana.

ABSTRACT | The growth of urban space of Zaragoza during the first fifteen years of the 21st century is characterized by its socio-spatial fragmentation at several scales, a signifcant feature of the neoliberal urbanism. The growth model of the city is composed of large monofunctional urban fragments attached to the existing urban space by the main traffic routes. These ways and other physical or perceived obstacles interrupt the continuity with the consolidated urban space, especially for the movement of people. Nevertheless, this pattern allows the connection of the new spaces with the local urban environment but, at the same time, promotes the social segregation and fosters a polycentric functional model based on travel by private car.

KEYwORDS | urban fragmentation, urban planning, urban periphery. 


\section{Introducción}

En este artículo se estudia la fragmentación del espacio urbano de la ciudad de Zaragoza, entendida como proceso y resultado de la aplicación en la ciudad de principios y prácticas propias del sistema económico neoliberal (o posfordista) (Pinson \& Morel Journel, 2016) que han conformado el desarrollo urbano de muchas ciudades desde finales del siglo xx en bastantes países del mundo (Schneider \& Woodcock, 2008), entre ellos España (Artigues et al., 2007; Gurovich, 2013; Hidalgo \& Janoschka, 2014; Vives \& Rullan, 2014).

En Espańa, el espacio urbano, y el espacio construido en general, han registrado transformaciones excepcionales durante el periodo estudiado en este trabajo, tanto por su gran magnitud y diversidad como por las múltiples secuelas negativas que han dejado, en el territorio y en las economías y sociedades locales, tras el desplome de la actividad inmobiliaria a raíz de la Gran Recesión iniciada en 2007 (Argullol, 2012; Burriel, 2015; Gurovich, 2013; Nel.lo \& Donat, 2014; Salom Carrasco \& Pitarch Garrido, 2014; Schulz-Dornburg, Fernández-Tabales \& Cruz Mazo, 2013).

El estudio del desarrollo urbano de Zaragoza en este periodo reviste gran interés por la envergadura de las intervenciones y porque, junto con aspectos comunes con procesos habidos en otras grandes ciudades, presenta rasgos propios que dan lugar a un caso diferenciado. Por otro lado, el inicio del periodo estudiado coincide, grosso modo, con la aprobación del Plan General de Ordenación Urbana de 2002, vigente con la revisión de 2008 (texto refundido).

La fragmentación urbana ha devenido en una noción fundamental para caracterizar los procesos neoliberales y sus efectos en las ciudades, tanto los que generan diferencias sociales crecientes (Borsdorf \& Hidalgo, 2010; Capron \& González Arellano, 2006; Janoschka, 2002; Jirón \& Mansilla, 2014; Valdés, 2007) como los que conducen a la formación de territorios urbanos cuarteados (Marcuse, 2009) y su relación con la segregación y polarización de la sociedad. La fragmentación urbana se relaciona con la globalización económica y cultural y se manifiesta, entre otros contenidos, en múltiples formas de estructuración social, en el fraccionamiento de la política y gobernanza de las ciudades y en la compartimentación física y funcional del espacio construido. En cada ciudad la interacción de factores generales y locales genera diferencias en los modos y efectos de la fragmentación, que pueden ser más que circunstanciales (Harrison, 2013, p. 17).

Con este contexto, se aborda aquí el estudio del proceso de trasformación urbana de la ciudad de Zaragoza durante el primer quindenio del siglo XxI con los siguientes objetivos: (i) mostrar la relación entre las intervenciones del planeamiento urbano y la aparición o refuerzo de procesos de fragmentación; (ii) identificar y caracterizar los nuevos desarrollos urbanos en términos de fragmentación espacial de los usos del suelo a varias escalas; y (iii) valorar la influencia de esta fragmentación en algunos tipos de relación social, en particular los socioeconómicos, y en la estructura espacial de las densidades de población.

En este trabajo se mantiene que durante estos años, en dos etapas claramente diferenciadas, la planificación urbana y los proyectos realizados en Zaragoza han seguido principios y formas neoliberales, semejantes a los de otras muchos ciudades, 
pero también se admite que las condiciones locales -como la presencia de grandes ejes de crecimiento y fijación espacial, naturales y construidos; la enorme superficie del municipio; el gran peso económico y territorial de los grandes proyectos; la inercia en las formas del crecimiento; y otras- han producido una combinación específica de continuidad y ruptura con el orden socioespacial y funcional preexistente. En otras palabras: la considerable expansión urbana reciente se ha llevado a cabo mediante la creación de grandes fragmentos cuya textura difiere de la del tejido urbano tradicional. Estos se localizan en el margen urbano, no aislados ni alejados, sino adyacentes a la ciudad consolidada, aunque rompen la continuidad espacial de esta. Esta modalidad de fragmentación física sin dispersión espacial genera sus propias influencias en la organización social y funcional de la ciudad, en particular en las áreas de contacto con el tejido urbano preexistente.

Los resultados de esta investigación contribuyen a conocer mejor la naturaleza multiescalar de la fragmentación del tejido urbano y sus conexiones con la organización socioespacial de la ciudad. En el caso de Zaragoza, la fragmentación no incide tanto en la reducción de la cohesión social en general como en los modos de relación social de proximidad, impulsando la formación de centralidades en el margen de la ciudad; a la vez, la fragmentación espacial actúa como medio de diferenciación de espacios (por segmentación económica, por la imagen que proyectan y es percibida, etcétera).

Los contenidos de este artículo están organizados del modo siguiente. En la primera sección se especifica el alcance de los conceptos utilizados. En la siguiente se describe la metodología seguida. En la tercera se exponen las principales ideas inspiradoras del desarrollo urbano reciente. En la cuarta se identifica y caracteriza la fragmentación urbana y se valoran sus principales impactos. En la última, se exponen las conclusiones y se proponen líneas de investigación futuras.

\section{La fragmentación urbana como noción multidimensional}

El marco general de estudio de la fragmentación urbana está constituido por el conjunto de transformaciones socioeconómicas que, desde el último tercio del siglo pasado, están conformando el denominado régimen de acumulación flexible (Castells, 1991; Harvey, 1989; Sassen, 1991).

Para este trabajo son relevantes los procesos involucrados en la creación de nuevas formas espaciales de la producción y de la organización de la sociedad, a todas las escalas, por su relación con la fragmentación urbana. En particular, cabe destacar la globalización económica y cultural, la tercerización de la economía y la consolidación de la ciudad como lugar de inversión intensiva de capitales públicos y privados (De Mattos, 2010; Duranton \& Puga, 2004; Hidalgo \& Janoschka, 2014; May, 1997; Moulaert, Scott \& Farcy, 1997).

La fragmentación urbana es un tema central de los debates sobre la reestructuración de la ciudad en el marco del sistema económico neoliberal, aunque la noción se ha convertido en una categoría comodín debido a la gran diversidad de contextos y a su uso ambiguo: como sinónimo o compartiendo significado con conceptos como segregación, dispersión urbana, ciudad archipiélago, segmentación, polarización 
socioespacial, etcétera (Capron \& González Arellano, 2006; Navez-Bouchanine, 2002a; Valdés, 2007). Por ello, es necesario explicitar el sentido con que se aplica en cada investigación.

El concepto de fragmentación urbana es complejo y de límites difusos, pues combina contenidos sociales, políticos y espaciales. En el trabajo de Navez-Bouchanine (2002b) se trata la génesis, significado y enfoques de utilización, así como los límites explicativos del concepto. Esta autora distingue dos grandes áreas de uso: por una parte, la social, en la que denota la ruptura de una unidad social urbana (real o supuesta); y, por otra, la urbana, que hace referencia al fraccionamiento de la gobernanza de las ciudades, la privatización de espacios para la relación social y sus implicaciones en la organización socioespacial de las ciudades.

El encuadre teórico anterior pone de manifiesto, por un lado, la gran capacidad descriptiva de la expresión "fragmentación urbana”; y, por otro, su fuerte carga para valorar los proyectos e intervenciones en las ciudades.

En la mayor parte de los trabajos empíricos, la fragmentación urbana se interpreta, tanto en su significado social como en el espacial, como una consecuencia, casi inevitable, de la globalización y la creciente competencia entre ciudades que aceleran la circulación del capital y la maximización de los retornos de las inversiones mediante el crecimiento y trasformación de las ciudades (Harrison, Huchzermeyer, Mayekiso \& Sholto-Douglas, 2013). Además, esta tendencia dominante considera la fragmentación urbana (social, política y espacial) como una cualidad negativa de las ciudades: de forma expresa o subentendida significa desorden, desconexión, exclusión o incoherencia. Tal valoración presupone la existencia, pasada o presente, de una entidad urbana integrada desde el punto de vista social y político, coherente, orgánica y continua en el orden funcional y espacial, que sirve como modelo por alcanzar. Este supuesto es, en muchos estudios, un axioma más que una realidad.

Este uso y conceptualización de la fragmentación urbana como una cualidad estática del espacio construido y del espacio social han recibido críticas por su aplicación automática y repetitiva y por su sentido ambiguo en muchas ocasiones (Capron \& González Arellano, 2006; Jirón \& Mansilla, 2014; Valdés, 2007). En el marco de la globalización, se ha elaborado una metanarrativa que aplica el concepto de fragmentación urbana de forma casi determinista y absoluta para explicar todo tipo de cambios urbanos y a todas las escalas, y minimiza la influencia de factores locales que solo dan cuenta de cambios meramente circunstanciales. Sin embargo, y como han evidenciado algunas visiones críticas, las condiciones locales pueden generar modelos de trasformación propios (Low \& Barnett, 2000; Marcuse \& Van Kempen, 2000), de los que no dan cuenta los procesos de globalización.

Estas y otras limitaciones han llevado a precisar contextos en los que el concepto de fragmentación urbana sea fructífero para entender los procesos urbanos neoliberales (Michelutti, 2010). En este sentido, es muy útil y aplicable al presente trabajo la distinción propuesta por Capron y González Arellano (2006) entre "partes" diferenciadas de las ciudades, pero interconectadas por múltiples flujos de "fragmentos" que tienden a la separación física y al aislamiento funcional. Los autores también destacan el valor de las prácticas cotidianas en la integración de las partes y fragmentos urbanos. Deffner y Hoerning (2011) también proponen relacionar la 
fragmentación urbana con las prácticas cotidianas de las personas y los modos en que se producen y reproducen la cohesión social y las formas de asociación, disociación y sistemas de relaciones asimétricas que coexisten en las ciudades contemporáneas. Finalmente, Jirón y Mansilla (2014) señalan que las intervenciones urbanísticas no solo fragmentan el espacio, sino también, y en relación con ello, el uso del tiempo de las personas, por las transformaciones urbanas en la movilidad -física o digital(Gaggiotti, Kostera, Bresker \& San Román, 2015; Lussault, 2017; Retaillé, 2009), en la integración de las redes físicas y virtuales, en la decisión y organización del individuo-colectivo, o en la pluralidad territorial.

A pesar de la persistencia de dificultades metodológicas para medir y valorar la fragmentación urbana (Capron \& González Arellano, 2006), los trabajos empíricos han incrementado, paulatinamente, la relación de indicadores disponibles a medida que se ha ampliado el campo semántico del concepto. La compartimentación política se valora mediante la diversidad de instituciones, normativa y organizaciones que participan en la gobernanza urbana. La fragmentación espacial se identifica y caracteriza a partir de elementos lineales que actúan como barreras y por la homogeneidad de los usos del suelo, entre otros. Hay que destacar también la importancia que adquiere la percepción de un espacio como fragmento diferenciado del resto de la ciudad (Deffner \& Hoerning, 2001). A microescala, la fragmentación se estima por la superficie ocupada por los espacios vacíos y no edificados y, sobre todo, por la intensidad y configuración de los espacios vallados (Navez-Bouchanine, 2002b).

En el presente trabajo entendemos que la fragmentación espacial y de los usos del suelo observables en el desarrollo urbano recientes de Zaragoza se relaciona, directa e indirectamente, con la globalización económica y cultural. La trasposición de determinadas ideas sobre la ciudad mediante proyectos sancionados por el planeamiento ha producido grandes fragmentos monofuncionales que han modificado algunas prácticas sociales y el modelo funcional. Aparte de los juicios de valor que pueda merecer el proceso de fragmentación y sus connotaciones políticas, lo cierto es que sus efectos influyen en la ciudad y en la vida de los ciudadanos.

\section{Metodología y datos}

La medición de la fragmentación física del espacio urbano se lleva a cabo, básicamente, mediante indicadores procedentes del ámbito de análisis de la forma urbana (Angel, Parent \& Civco, 2007; Batty, Chin \& Besussi, 2002; Chin, 2002; Inostroza, Baur \& Csaplovics, 2013; Muñiz \& García-López, 2013; Sapena Moll \& Ruiz Fernández, 2015; Reis, Silva \& Pinho, 2016; Torrens, 2008). Sus múltiples impactos se han estimado a partir de técnicas de medición de la segregación socioespacial y de métodos cualitativos.

La metodología utilizada en el presente artículo es sencilla y directa, acorde con los objetivos planteados. En primer lugar, a partir del análisis de los planes estratégicos se argumenta su conexión con la globalización y se muestra la modalidad dominante de intervención en la ciudad en grandes piezas (fragmentos) relativamente aisladas y de usos del suelo homogéneos. Después, se identifican elementos físicos o percibidos que fragmentan el espacio construido. Finalmente, se consideran 
algunas manifestaciones relacionadas con fragmentación; en concreto, la redistribución de la población y la aparición de centralidades comerciales en la periferia, consideradas síntomas de un agudo proceso de fragmentación (Capron \& González Arellano, 2006).

La identificación y caracterización de la fragmentación urbana se estiman del modo siguiente:

a. A escala urbana. Los grandes fragmentos urbanos se delimitan mediante la combinación de: (i) elementos lineales que constituyen bordes que interrumpen la continuidad con el espacio urbano preexistente y constituyen obstáculos a veces infranqueables para los peatones; en concreto se han considerado las autovías, vías férreas y grandes espacios verdes y vacíos; (ii) usos de suelo homogéneos con extensión superior a una hectárea (3,33 ha, superficie media de los parches de usos del suelo del espacio tradicional). Como criterio complementario se ha tenido en cuenta que un espacio sea percibido como fragmento diferenciado del resto del espacio urbano. Esta información se ha obtenido en talleres con estudiantes del grado de Geografía y Ordenación del Territorio y del máster Universitario en Ordenación Territorial y Medioambiental de la Universidad de Zaragoza, así como en encuestas y entrevistas realizadas en centros cívicos con residentes de los barrios.

b. A microescala. En este caso, la fragmentación se ha estimado mediante la existencia de espacios vallados, identificados a partir de imágenes de satélite (Plan Nacional de Ortofotografía Aérea [PNOA], 2012; GoogleEarth, 2014) y de trabajo de campo, y por el índice de fragmentación del espacio edificado (Openness index), que se define por la proporción de superficie edificada en relación con la superficie total de un círculo de un kilómetro de radio en torno a cada píxel con edificación (Angel et al., 2007). En este caso, teniendo en cuenta el tamaño medio de las manzanas y la extensión del espacio edificado, se ha utilizado un radio de $250 \mathrm{~m}$, que recoge mejor las variaciones locales, que son las que interesan en este estudio. Este índice de espacio abierto varía entre 0, que expresa la ausencia de edificación, y 1, que indica que el área del círculo del radio especificado en torno a un pixel está completamente edificada.

Entre los efectos asociados a la fragmentación urbana se han estudiado los cambios en la distribución espacial de la población y la creación de centralidades en los márgenes del espacio urbano continuo. Los primeros se han analizado mediante las variaciones espaciales de la densidad en relación con el centro urbano (Plaza de España) y mediante el índice $\rho$ de compacidad de la población (Bertaud, 2001), cuya ecuación es la siguiente:

$$
\rho=\Sigma d_{i} p_{i} / P C
$$

Donde: $\mathrm{d}_{\mathrm{i}}$ : distancia desde el centro funcional urbano y la residencia de la población residente en $i$; $\mathrm{p}_{\mathrm{i}}$ : población del lugar $i$; C: promedio de la distancia de la población al centro de una distribución ideal en forma de cilindro, cuya superficie de la base es igual a la de la zona de estudio y la altura corresponde al valor de densidad media 
de población. Este valor, obtenido por cálculo integral, es aproximadamente $2 / 3$ del radio del círculo; P: población total.

Este indicador es muy útil para comparar, en el tiempo y en el espacio, las variaciones del agrupamiento de la población en torno a un punto, habitualmente el centro de la ciudad. Para tal fin, el índice relaciona la distancia media de la población en línea recta al centro urbano con esta misma magnitud, pero calculada para la misma población distribuida de manera uniforme en un cilindro cuya base tiene la misma superficie que la ciudad. Esta construcción no implica que el cilindro sea un prototipo de ciudad eficiente, sino que es un artefacto para normalizar los resultados. Los valores de $\rho$ inferiores a 1 indican que la población se concentra en torno al centro establecido en relación con una distribución teórica cilíndrica; los valores superiores a 1 indican tendencias a la dispersión. Para este estudio se ha fijado el centro en la Plaza de España (centro funcional y tradicional de la movilidad de la ciudad) y la residencia de la población en los centroides de las manzanas.

Los datos temáticos relativos a la fecha de construcción, así como a su localización espacial y usos del suelo, se han obtenido del catastro, a través de las variables del "registro del bien inmueble", generalizados a la "parcela urbana" y a la "masa" (manzana urbana). Las especificaciones del formato de archivo se describen en el modelo de datos del catastro (Dirección General del Catastro, 2011). La configuración espacial de las "áreas de desarrollo" del Plan General de Ordenación Urbana de Zaragoza (PGOU 2008; texto refundido del PGOU 2002) y otros datos sobre las mismas, proceden del Sistema de Información Urbana del Ministerio de Fomento. Los usos del suelo se han obtenido del Sistema de Información de Ocupación del Suelo de Espańa (sıose) y corresponden al año 2011. Los datos de población se han obtenido del "Padrón Municipal de Habitantes", publicado por el Instituto Nacional de Estadística y de los datos publicados por el Observatorio Municipal de Estadística del Ayuntamiento de Zaragoza.

\section{El proceso de fragmentación: ideas, etapas y principales realizaciones}

La producción material de los fragmentos urbanos se enmarca en un denso entramado de ideas, agentes y normas que legitiman y prefiguran los proyectos urbanos.

Aquí se recogen las propuestas formalizadas en la planificación estratégica más difundidas y defendidas por los medios de comunicación. Las más importantes han sido asumidas por el PGOU (2002) y caracterizan la reciente "metamorfosis urbana" de Zaragoza (De Miguel González, 2015).

\section{La modernización como idea articuladora del tiempo y del espacio.}

\section{La planificación estratégica}

La "modernización" constituye la idea-puente que da continuidad temporal a las iniciativas desarrolladas aqui y ahora con las del pasado, las proyecta hacia el futuro y, a la vez, fundamenta la conexión de la ciudad con la dinámica mundial.

Los antecedentes próximos de las transformaciones recientes de la ciudad de Zaragoza se pueden situar a mediados del siglo XIx (1856, llegada del ferrocarril). Los múltiples proyectos desarrollados durante la segunda mitad del siglo xix y primeras 
décadas del siglo xx pretendían "modernizar" la sociedad y el espacio urbano de Zaragoza, es decir, incorporar la ciudad al nuevo modo de producción industrial.

La noción de "modernidad" ha inspirado sucesivas oleadas de intervenciones urbanas desde finales del siglo xIx, que transformaron radicalmente el espacio urbano anterior (Biel, 2004; Faus, 1978; García-Lasaosa, 1979). Entre los grandes proyectos de esta etapa impulsores de cambios urbanos cabe mencionar la Exposición HispanoFrancesa (1908) (Forcadell-Álvarez, 2004; Jiménez-Zarzo, MartínezBuenaga, Martínez-Prades \& Martínez-Verón, 2004), ejemplo para la Exposición Internacional de 2008 (Expo 2008).

Otra importante oleada modernizadora se produjo a partir de la constitución de los ayuntamientos democráticos (1978). El PGOU de 1986 contiene determinaciones fundamentales del desarrollo urbano actual. Entre otras, el plan dota de gran superficie de suelo urbanizable en los márgenes de la ciudad compacta, aborda múltiples proyectos de reforma interior, contempla la creación de numerosos equipamientos y servicios e impulsa un modelo funcional policéntrico (Ayuntamiento de Zaragoza, 1992).

El proceso reciente de trasformación urbana de Zaragoza, al igual que en otras muchas ciudades, ha utilizado los planes estratégicos como instrumentos para definir objetivos y propuestas de desarrollo de la ciudad y del entorno que, posteriormente, se han incorporado a los planes de ordenación.

Para Zaragoza y su entorno, la entidad Ebrópolis (sociedad mixta, con participación de las administraciones y organismos públicos, organizaciones sociales y empresariales y entidades privadas) ha redactado dos planes estratégicos: el Plan Estratégico de Zaragoza y su entorno 1998-2010 (Ebrópolis, 2006) y el Marco estratégico de Zaragoza 2020 (Ebrópolis, 2011), cuyos contenidos se resumen en la tabla 1. Estos planes, particularmente el primero, han inspirado los principales proyectos relacionados con el desarrollo económico, social y urbanístico de Zaragoza en los quince ańos transcurridos del siglo xxI.

\section{TABLA I | Resumen de los contenidos de los planes estratégicos de Zaragoza}

\begin{tabular}{|c|c|}
\hline $\begin{array}{l}\text { PLAN ESTRATÉGICO DE } \\
\text { ZARAGOZA Y SU ENTORNO } \\
\text { I998-20IO (REV. 2006) }\end{array}$ & MARCO ESTRATÉGICO ZARAGOZA 2020 \\
\hline $\begin{array}{l}\text { Visión estratégica } \\
\text {-Líneas estratégicas }\end{array}$ & \multirow{2}{*}{$\begin{array}{l}\text { Visión de Zaragoza en 2020: } \\
\text { "Es la de una ciudad y su entorno como un espacio equilibrado, } \\
\text { que se posiciona como un lugar clave y de referencia en un mundo } \\
\text { globalizado, apoyándose en unos valores propios, fundamentados en } \\
\text { la creatividad, atractividad y conectividad". (p. 20). }\end{array}$} \\
\hline $\begin{array}{l}\text { Posicionamiento exterior } \\
\text {-Desarrollo accesos } \\
\text {-Desarrollo identitario } \\
\text {-Desarrollo relacional }\end{array}$ & \\
\hline $\begin{array}{l}\text { Desarrollo sostenible } \\
\text {-Progreso social } \\
\text {-Progreso cultural y educativo } \\
\text {-Progreso económico } \\
\text {-Desarrollo territorial } \\
\text {-Desarrollo ambiental }\end{array}$ & $\begin{array}{l}\text { Ejes estratégicos: } \\
\text { 1. Zaragoza, Ciudad de los Ciudadanos } \\
\text { 2. Zaragoza, Ciudad de Alianzas } \\
\text { 3. Zaragoza, Ciudad Innovadora } \\
\text { 4. Zaragoza, Ciudad-Territorio y Ciudad-Global } \\
\text { 5. Zaragoza, Ciudad-Sostenible } \\
\text { 6. Zaragoza, Ciudad Comunicativa }\end{array}$ \\
\hline
\end{tabular}

FUENTE EBRÓPOLIS 2006, EBRÓPLIS 20 II 
Las líneas maestras perfiladas en la planificación estratégica de Zaragoza contienen intervenciones encaminadas a conformar y presentar la ciudad como un espacio óptimo para el desenvolvimiento de determinadas actividades económicas a escala global, y para atraer a la que Florida (2003) denomina "clase creativa", en un contexto mundial muy competitivo.

Para lograr estos objetivos, se propone un ambicioso programa de construcción de infraestructuras y equipamientos, encaminado a cambiar la escala de las tradicionales ventajas de localización de la ciudad de Zaragoza. La función de nodo de intercambio entre grandes áreas geoeconómicas peninsulares y con el sur de Francia, desempeñada tradicionalmente por la ciudad, ha de extenderse al continente europeo y al mundo. Los proyectos de mayor envergadura se han desarrollado mediante iniciativas conjuntas público-privadas, pero han supuesto cuantiosas inversiones públicas para incrementar las ventajas de localización de Zaragoza (figura 1).

\section{FIGURA I | Usos generales del suelo}

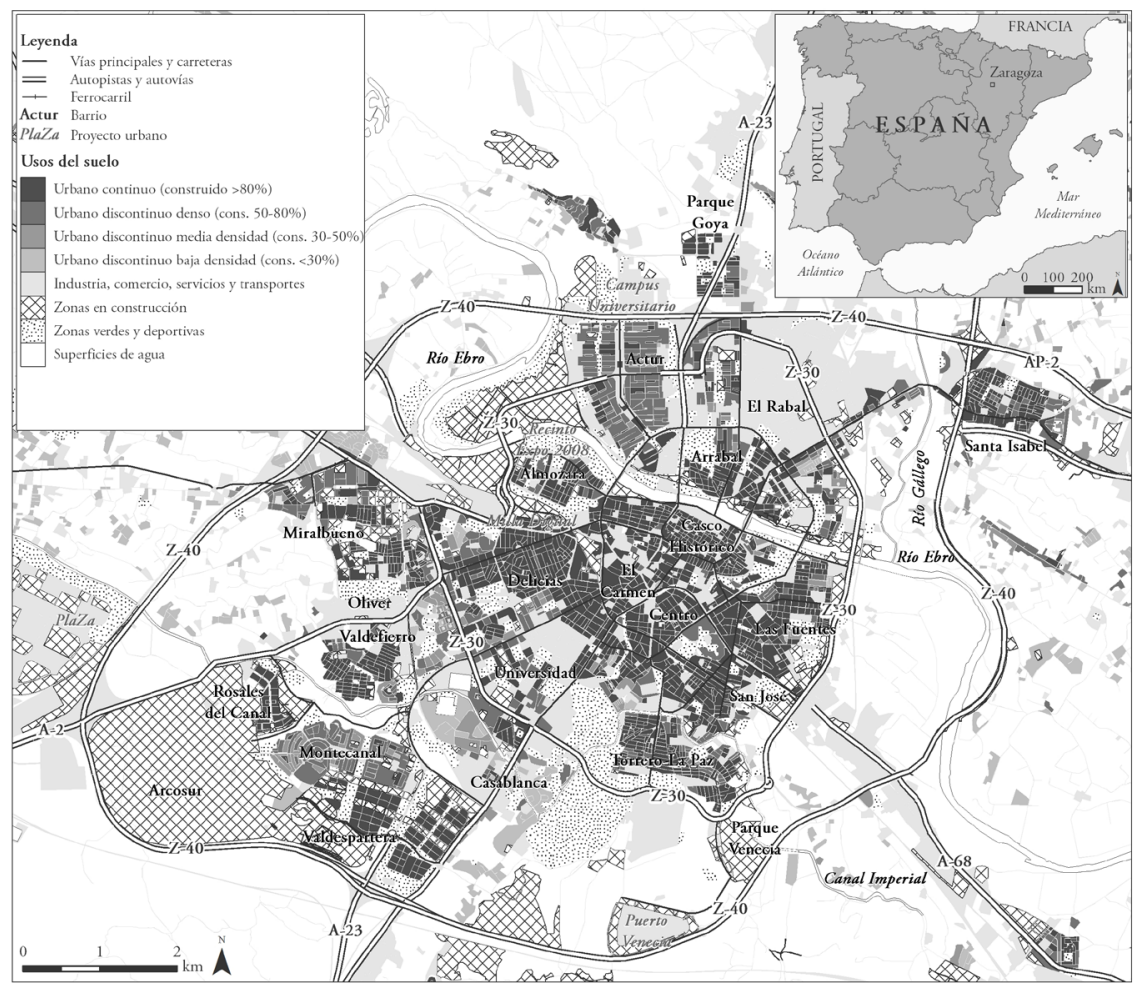

FUENTES URBAN ATLAS 2006, CORINE LAND COVER 2OI2, AGENCIA EUROPEA DE MEDIO AMBIENTE, IGN, IGEAR. ELABORACIÓN PROPIA

Sin embargo, en varios casos emblemáticos, el desarrollo de los proyectos se ha desviado bastante de los modelos diseńados, ya que los planes estratégicos contienen algunas propuestas en materia territorial y social que son más una lista de deseos 
que proyectos bien fundados. De hecho, asocian en forma automática la mejora de la conectividad a la mejora económica y social o dan por supuesto que la mera existencia de espacios y contenedores físicos para determinadas actividades es condición suficiente para crear o atraer empresas.

La planificación estratégica de Zaragoza también contempla, como se hace en otros muchos planes estratégicos, la creación de una marca que identifique a la ciudad como un lugar de excelencia para emprender negocios de alcance global. Para desarrollar y promocionar la marca Zaragoza, se creó la sociedad mixta Zaragoza Global (2008), con la participación del Gobierno de Aragón, el Ayuntamiento de Zaragoza y la Cámara de Comercio de Zaragoza, cuya vida fue corta, pues fue liquidada en 2012. Los resultados de esta iniciativa han sido parcos, pues la marca y el logotipo son poco conocidos y usados entre los empresarios y el público en general.

Si a la celebración de un evento excepcional, como la Exposición Internacional de 2008, se ańade la desmesura y sobredimensión de algunos proyectos, junto a varios episodios de corrupción, se entiende fácilmente que la realización de estas obras haya sido, per se, el principal objeto de negocio inmediato. Además, el contexto general de crisis económica redujo drásticamente, a partir de 2008, las expectativas de negocio de los principales proyectos, que no han sido finalizados, dejando con ello un paisaje urbano con importantes vacíos (Bellet \& Alonso, 2016).

Actualmente se está abordando la "Estrategia Zaragoza +20 ", con una profundización en los ámbitos de la lucha contra el cambio climático, de la economía del conocimiento y de la innovación, y dando continuidad al modelo de ciudad sostenible de urbanismo compacto que posibilita una calidad de vida equitativa para sus habitantes.

\section{Desarrollo urbano reciente de Zaragoza: contexto y principales realizaciones}

En el desarrollo urbano de Zaragoza en el siglo xxi se diferencian con claridad dos etapas, separadas por la celebración de la Expo 2008, distintas por su contexto socioeconómico y por el volumen y tipo de intervenciones. Ambas comparten un marco legal denso y complejo, originado por una respuesta institucional a los problemas de ordenación territorial y urbana compulsiva en la promulgación de normas, y fragmentada en varios niveles de competencias y múltiples instrumentos, que ha dejado un paisaje de "hipertrofia normativa regional" (Calderón, 2012), y también nacional y local, poco eficaz y bastante inestable ${ }^{1}$ (figura 2).

En el periodo estudiado, el crecimiento de la población del municipio de Zaragoza y de los de su entorno ha sido moderado y desigual en el tiempo y en el espacio. Los datos del padrón municipal muestran que la evolución reciente de la población del municipio de Zaragoza ha seguido una tendencia ascendente entre 2001 (610.976 habitantes) y 2012 (704.887 habitantes), seguida de un ligero descenso o estabilidad hasta 2015 (702.123 habitantes). Las tasas de crecimiento anual acumulado alcanzaron el 1,58\% en el quinquenio 2001-2006, para descender al 1,10\% entre 2006 y 2012, y tornarse negativas (casi sin variación) desde 2012 a $2015(-0,01 \%)$. 
FIGURA 2 | Normativa y principales proyectos de desarrollo urbano de Zaragoza entre 1998 y 2015

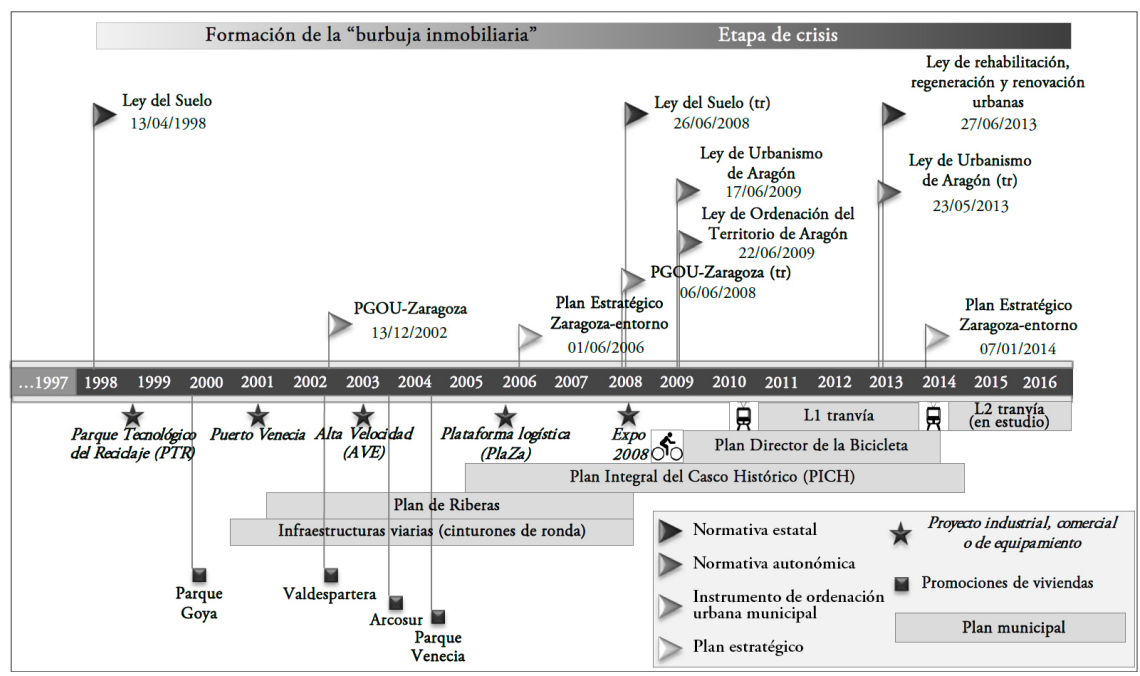

FUENTE ELABORACIÓN PROPIA

Los 15 municipios restantes del Área Urbana de Zaragoza (Ministerio de Fomento, 2010) han tenido un crecimiento demográfico más vigoroso, pues su población casi se ha duplicado entre 2001 (38.944 habitantes) y 2014 (74.868 habitantes), aunque los valores absolutos son modestos, comparados con los de las áreas urbanas españolas más dinámicas. Al igual que en el municipio central, la trayectoria de la población ha sido al alza entre 2001 y 2012, con tasas de crecimiento anual en torno al 6\%, para reducirse al 1,2\% entre 2012 y 2014.

La desaforada actividad de construcción y la aceptable marcha de otros sectores económicos, en particular el industrial y los servicios, junto con un clima de optimismo colectivo y la intensa actividad de los promotores urbanísticos facilitada por las instituciones (Calvo-Palacios, Pueyo-Campos \& Zúńiga-Antón, 2011), impulsaron el desarrollo de grandes proyectos de infraestructura, urbanismo, equipamientos, comercio, oficinas y viviendas, que se presentaron como necesarios para mejorar la calidad de vida y la competitividad de Zaragoza a escala mundial.

\section{La etapa expansiva: la ampliación del espacio urbano}

La mayor parte de las intervenciones, sobre todo en infraestructuras y viviendas, se realizaron en los años que median entre principios de este siglo y la celebración de la Expo 2008, aunque algunas se habían iniciado con anterioridad. En este periodo el espacio urbanizado de la ciudad de Zaragoza y de los municipios del entorno se incrementó de forma considerable, para usos residenciales, industriales y equipamientos: entre 2001 y 2015 se ańadieron unas 3.250 ha de espacio urbanizado, superficie algo menor que la de todo el espacio continuo en 2001 (3.910 ha). ${ }^{2}$

2 Estimación propia a partir de las fuentes indicadas en el apartado de metodología; el espacio urbano continuo es el englobado en el cinturón Z-30. 
El principal grupo de intervenciones se ha concentrado en torno a dos ejes que constituyen la quintaesencia de la posmodernidad. Por un lado, el grueso de las intervenciones ha consistido en la creación de infraestructuras y equipamientos que facilitan la movilidad a todas las escalas (terminal aeroportuaria, estación intermodal, plataforma logística, puerto seco, circunvalaciones, tranvía); por otro, se han diseńado espacios para atraer actividades y agentes relacionados con la economía del conocimiento y la aplicación de las nuevas tecnologías de la información (Centro de Arte y Tecnología Etopia; incubadoras de empresas, espacios para actividades terciarias, etcétera), ya que "la sociedad a la que queremos dirigirnos los zaragozanos fundamenta todas sus reflexiones en la apuesta decidida por las nuevas tecnologías y la inserción en la sociedad del conocimiento" (destacado en el original) (Ebrópolis, 2006, p. 29). Mención especial merece el acondicionamiento del espacio de la Expo 2008 y el Plan de Acompańamiento compuesto por un amplio programa de inversiones urbanísticas, entre las que destacan los proyectos para la recuperación de las riberas del Ebro, la construcción de varios puentes y la renovación de otras infraestructuras y espacios urbanos (Gómez \& Sanaú, 2009). Además, la celebración de este evento y otros factores, como la mejora de la accesibilidad, actuaron como un fuerte revulsivo en otros ámbitos económicos, como la hostelería, las oficinas e incluso la promoción de viviendas. Esta modalidad de desarrollo urbano ha sido calificada como "urbanismo-espectáculo" (Del Romero, 2010).

Por otro lado, se han puesto en marcha grandes proyectos para impulsar actividades económicas que aprovechen la buena accesibilidad de la ciudad. Para ello se han creado enormes piezas de suelo industrial, posibles por la gran extensión del término municipal, soldadas a la autovía de circunvalación más externa (z40), como la plataforma logística Plaza (1.283 ha de superficie total, desarrollada mediante convenio entre instituciones públicas y agentes privados), el Parque Tecnológico del Reciclado (PTR), promovido por iniciativa privada (836 ha de superficie total), y otros (López-Escolano, Pueyo-Campos, Valdivielso-Pardos \& Hernández-Navarro, 2015). El grado de ocupación de cada polígono es diferente, y alguno de ellos está prácticamente vacío. En el municipio se puede estimar que el suelo industrial aún libre de edificación rebasa las 500 ha. Si se considera el conjunto del área urbana, la superficie de suelo industrial "yermo" se incrementa notablemente. También ha aumentado considerablemente el espacio disponible para oficinas, buena parte del cual se encuentra hoy sin apenas uso (Torre Aragonia, World Trade Center, Trovador, Edificio de la Confederación de Empresarios de Gómez Laguna 25, Expo Zaragoza Empresarial, zona de servicios de Plaza, Centro Empresarial San Lamberto).

Un aspecto destacable del desarrollo urbano del periodo estudiado se encuentra en la fuerte presencia de convenios entre instituciones o empresas públicas para llevar a cabo grandes proyectos (Plaza, Zaragoza Alta Velocidad, Consorcio Expo 2008) o con agentes privados (el PGOU 2008 de Zaragoza recoge 33 convenios desde el año 2000). Esta colaboración público-privada se ha interpretado, generalmente, como una orientación neoliberal de la gobernanza urbana, que fragmenta el proceso de toma de decisiones sobre la ciudad y transfiere competencias y servicios desde el sector privado al público. 
La construcción de viviendas y las obras de urbanización del suelo correspondientes han sido otros dos pilares sobre los que ha descansado el crecimiento de los primeros ańos de la etapa estudiada, tanto en Zaragoza como en los municipios del área urbana. La vivienda fue un producto de inversión bastante generalizado, incluso entre pequeños inversores, desde mediados de los años noventa hasta 2007, debido a los elevados beneficios que producía en cortos periodos de tiempo el capital invertido, en un mercado en continua expansión lubrificado por la abundante financiación facilitada por el sistema bancario. La etapa de crisis ha mostrado las consecuencias perversas de este proceso autoalimentado ("burbuja”), cuya cara más dolorosa aparece en los desahucios.

Como se observa en la tabla 2, las licencias para la construcción de nuevas viviendas crecieron a buen ritmo desde 2000 hasta 2007, para desplomarse en los años siguientes: las licencias para nueva edificación residencial de 2013 apenas alcanzan la cuarta parte de la superficie aprobada en 2007.

TABLA 2 Licencias para la construcción de edificios y rehabilitación según tipo de obra en el municipio de Zaragoza, 2000-2013

\begin{tabular}{|c|c|c|c|c|c|c|c|c|c|}
\hline \multirow{2}{*}{ AÑO } & \multirow{2}{*}{ EDIFICIOS NUEVA PLANTA } & \multicolumn{2}{|c|}{ SUPERFICIE (M ${ }^{2}$ X OOO) } & \multicolumn{4}{|c|}{ VIVIENDAS } \\
\cline { 2 - 11 } & TOTAL & $\begin{array}{c}\text { RESI- } \\
\text { DENCIAL }\end{array}$ & $\begin{array}{c}\text { NO RESI- } \\
\text { DENCIAL }\end{array}$ & TOTAL & $\begin{array}{c}\text { RESI- } \\
\text { DENCIAL }\end{array}$ & $\begin{array}{c}\text { NO RESI- } \\
\text { DENCIAL }\end{array}$ & $\begin{array}{c}\text { NUEVA } \\
\text { PLANTA }\end{array}$ & $\begin{array}{c}\text { REHABI- } \\
\text { LITACIÓN }\end{array}$ & $\begin{array}{c}\text { DEMO- } \\
\text { LICIÓN }\end{array}$ \\
\hline 2000 & 876 & 802 & 74 & 1.130 & 998 & 132 & 5.488 & 172 & 476 \\
\hline 2001 & 841 & 742 & 99 & 970 & 797 & 173 & 5.059 & 153 & 453 \\
\hline 2002 & 888 & 843 & 45 & 1.331 & 1018 & 313 & 6.169 & 156 & 444 \\
\hline 2003 & 667 & 562 & 105 & 1.063 & 752 & 311 & 4.606 & 204 & 563 \\
\hline 2004 & 931 & 663 & 268 & 1.119 & 829 & 290 & 4.787 & 66 & 480 \\
\hline 2005 & 811 & 388 & 423 & 1.653 & 815 & 838 & 4.609 & 153 & 492 \\
\hline 2006 & 1359 & 899 & 460 & 2.166 & 1.468 & 697 & 8.642 & 186 & 500 \\
\hline 2007 & 1816 & 616 & 1.200 & 2.156 & 1.137 & 1.018 & 5.915 & 126 & 388 \\
\hline 2008 & 931 & 441 & 490 & 1.626 & 644 & 982 & 3.636 & 148 & 319 \\
\hline 2009 & 392 & 275 & 117 & 995 & 641 & 353 & 3.491 & 76 & 56 \\
\hline 2010 & 203 & 140 & 63 & 612 & 332 & 280 & 1.889 & 20 & 56 \\
\hline 2011 & 327 & 269 & 58 & 562 & 333 & 229 & 1.906 & 110 & 71 \\
\hline 2012 & 184 & 140 & 44 & 279 & 172 & 106 & 915 & 51 & 138 \\
\hline 2013 & 171 & 134 & 37 & 319 & 277 & 43 & 1.538 & 14 & 45 \\
\hline Total & 10.397 & 6.914 & 3.483 & 15.980 & 10.213 & 5.567 & 58.650 & 1.635 & 4.481 \\
\hline
\end{tabular}

FUENTE INSTITUTO ARAGONÉS DE ESTADÍSTICA (IAEST)

La mayor parte de la superficie construida para uso residencial se localiza en el espacio comprendido entre los cinturones Z-30 y Z-40, donde han nacido nuevos barrios, como Valdespartera (2003, 9.687 viviendas), Parque Venecia (2005, 4.103 viviendas) Arcosur (2004, 21.148 viviendas previstas; en 2015 se ha construido alrededor del 10\%), Rosales del Canal (2.330 viviendas previstas) o se han 
consolidado otros preexistentes como Montecanal (1998). Algunos barrios tradicionales, como Miralbueno, Oliver, Valdefierro y Santa Isabel, también se emplazan en esta franja; su posición periférica y sus limitadas conexiones con las redes principales de calles y carreteras alimentaban la percepción de barrios aislados, situación que ha variado con la ocupación por nuevas viviendas de espacios vacíos o antes industriales y por la mejora de su accesibilidad, conferida por las vías de circunvalación.

\section{Retorno hacia el espacio urbano consolidado}

La súbita aparición de la crisis económica y sus efectos han creado incertidumbre acerca de la viabilidad de algunos proyectos tal como fueron concebidos (Bellet \& Alonso, 2016). La suerte de cada uno ha sido diversa: algunos se han completado y funcionan aceptablemente, mientras que otros apenas han arrancado, como "Milla Digital" (Escolano \& Salvador, 2013). En 2015, el Parque Empresarial Dinamiza, creado para gestionar el espacio e instalaciones de la Expo 2008, está ocupado a los $67 \%$ de la superficie comercializada, la mitad de la misma por sedes y oficinas institucionales (juzgados, educación) trasladadas desde otros lugares de la ciudad, que dan trabajo a 3.000 personas. Por otro lado, algunos bloques de viviendas que estuvieron habitados unos meses hoy están cerrados, igual que algunas torres completas de oficinas levantadas al calor de la actividad asociada a la Expo 2008.

La actividad de urbanización y de construcción se desplomó una vez finalizada la Expo 2008 y las intervenciones de esta etapa se han concentrado en el espacio urbano consolidado, al socaire de los nuevos rumbos de la política urbanística, definidos por la rehabilitación y la sostenibilidad. En cuanto al suelo industrial, el PGOU 2008 de Zaragoza ańadió 438 ha de nueva edificabilidad, de las que en 2012 se había desarrollado el 38\%.

Buena parte de las actuaciones, más modestas que las de la etapa anterior, se han dirigido a la creación o mejora de equipamientos, especialmente zonas verdes; a la ampliación de la red de carriles para bicicletas; proyectos de renovación urbana en el marco del Plan Integral del Casco Histórico (PICH) (Ayuntamiento de Zaragoza, s/f) y del Plan Integral del Barrio Oliver (РіBO); y actuaciones puntuales de rehabilitación llevadas a cabo por Zaragoza Vivienda.

La construcción de la línea 1 del tranvía (2011-2013) ha mejorado la articulación norte-sur de la ciudad y ha reforzado la centralidad del casco histórico, al tiempo que ha modificado el paisaje urbano en la franja de su recorrido. También permitió mantener cierto tono en la actividad de construcción en años críticos para este sector.

El mercado de viviendas ya saturado, y con suelo urbanizado con capacidad residencial para bastante tiempo, ha registrado una fuerte y brusca caída desde 2008. La previsión de viviendas recogida en el PGOU 2008 (texto refundido) aparece en la tabla 3. La capacidad del suelo para viviendas está sobredimensionada, incluso a medio plazo, como también lo estaban las previsiones del PGOU de 1986. La Memoria del PGOU 2008 resalta este hecho: el parque residencial creció desde 1981 hasta 2001 en 80.203 unidades $(39,43 \%)$, en tanto que el número de habitantes lo hizo en 36.325 (6,35\%), de tal forma que en 2001 se alcanzó la ratio de 1 vivienda por cada 2,31 habitantes (excluidas las viviendas secundarias y ruinosas). Si se considera además el suelo no delimitado y el sujeto a convenio, se alcanzaría un índice de 
1,50-1,75 habitantes por vivienda, valores alejados de cualquier previsión razonable a medio plazo (Ayuntamiento de Zaragoza, 2008). Si a esta superficie residencial se le añade la prevista en los municipios del entorno, entonces la brecha entre lo proyectado y la realidad todavía se agranda más.

Ni las proyecciones del crecimiento demográfico, ni la creación de nuevos hogares ni la tasa de reposición de vivienda justifican las capacidades del suelo contempladas en el plan a medio y largo plazo, y más si se tiene en cuenta la oferta de viviendas en los municipios del entorno. No obstante, hasta 2012, en las "áreas de desarrollo" del PGOu 2008 se habían construido algo más de 6.500 viviendas de las 35.251 previstas, es decir, el 18,5\% del total (Ministerio de Fomento, s/f).

En resumen: el periodo estudiado se caracteriza por una gran actividad del sector de la construcción, especialmente desde finales de la década de 1990 hasta 2007, desarrollada en grandes proyectos de urbanización (infraestructuras, suelo industrial y para actividades terciarias) y en la construcción de viviendas. A continuación, se examinarán algunos efectos que ha producido en el espacio urbano preexistente y su organización.

TABLA 3 | Estimación de la capacidad de viviendas del PGOU de Zaragoza de 2008

\begin{tabular}{|c|c|c|c|}
\hline \multirow{2}{*}{ TIPO DE SUELO } & \multicolumn{3}{|c|}{ NÚMERO DE VIVIENDAS } \\
\hline & LIBRES & PROTEGIDAS & TOTAL \\
\hline 1. Suelo con planeamiento anterior recogido por el plan & 15.000 & 3.500 & 18.500 \\
\hline \multicolumn{4}{|l|}{ 2. Suelos ordenados por el plan } \\
\hline $\begin{array}{l}\text { a) Suelo urbano no consolidado } \\
\text { áreas de nueva ordenación (F, G) }\end{array}$ & 13.670 & 3.418 & 17.088 \\
\hline b) Suelo urbanizable delimitado & 3.162 & 1.054 & 4.216 \\
\hline c) Suelo urbanizable no delimitado $\left(^{*}\right)$ & 36.904 & 12.300 & 49.204 \\
\hline $\begin{array}{l}\text { d) Suelos sujetos a convenio } \\
\text { Valdespartera }\end{array}$ & 8.738 & $\begin{array}{c}\text { (no se cuantifica) } \\
2.912\end{array}$ & 11.650 \\
\hline Total $2(a+b+c)$ & 53.756 & 16.778 & 70.534 \\
\hline Total $1+2$ & 68.756 & 20.278 & 89.034 \\
\hline \multicolumn{4}{|l|}{ Capacidad a medio plazo } \\
\hline $\begin{array}{l}\text { Planeamiento recogido + suelo urbano no consolidado + } \\
\text { suelo urbanizable delimitado }\end{array}$ & 31.852 & 7.978 & 39.830 \\
\hline $\begin{array}{l}\left({ }^{*}\right) \text { CIFRA ESTIMATIVA OBTENIDA AL APLICAR LOS R } \\
\text { DELIMITADO. }\end{array}$ & ULTADOS & DEL SUELO DELIN & DO AL \\
\hline
\end{tabular}

\section{Valoración de los resultados: múltiples escalas e implicaciones de la fragmentación urbana}

La fragmentación urbana de Zaragoza se ha incrementado en los primeros quince años del siglo xxi como consecuencia de la creación de nuevos espacios que presentan diferencias por su modo de inserción en el tejido preexistente. Por una parte, se han formado bastantes retazos aislados en el término municipal, pequeńos y medianos, legales e ilegales, con usos residenciales, industriales y de servicios (Marín, 2009); 
por otra, se ha creado nuevo tejido urbano adyacente al espacio urbano continuo, pero con una textura distinta, precisamente por su carácter fragmentado.

La ampliación del espacio urbano de Zaragoza por grandes fragmentos no es un hecho nuevo, pero los creados recientemente se diferencian de los anteriores por su carácter monofuncional, por sus límites bien marcados por vías de comunicación u otros bordes físicos o percibidos, y por la compartimentación interna del espacio residencial mediante el cercado de las propiedades.

Entre otros aspectos, la configuración fragmentada se relaciona con la dispersión espacial de los empleos y de la residencia de la población en el municipio de Zaragoza y, especialmente, en su entorno metropolitano (Escolano, 2005), así como como con las modificaciones de la estructura espacial de las densidades de población. También influye en los notables cambios registrados en la organización funcional de la ciudad, tradicionalmente monocéntrica, que ha dado un giro significativo hacia el policentrismo a partir de la creación de núcleos de centralidad especializados — centros comerciales, universidades, hospitales, juzgados - en la interfase del espacio urbano continuo y los nuevos desarrollos fragmentados.

Sin embargo, a pesar de estos rasgos de clausura, la localización de estos fragmentos, contigua al espacio urbano continuo, facilita su conexión con los barrios del entorno, con los que existen lazos relativamente intensos, generados por el uso de equipamientos y servicios.

\section{Las escalas de la fragmentación}

La fragmentación reciente del espacio urbano de Zaragoza muestra, al menos, dos niveles de compartimentación física imbricados entre sí.

El primero está formado por grandes unidades monofuncionales de forma irregular, delimitadas por las principales vías de circulación y otros elementos lineales, que desde la década de 1990 se han ido adosando al núcleo urbano preexistente. Las circunvalaciones Z-30, que marca aproximadamente el límite físico y percibido del espacio urbano compacto tradicional, y Z-40, que hoy constituye el límite exterior de la mayor parte de la superficie de suelo urbanizable; junto a las autovías radiales (Huesca, Logrońo, Madrid, Valencia, Castellón y Barcelona) son las nervaduras que articulan este mosaico, entre sí y con el resto de la ciudad, y al mismo tiempo confinan los movimientos peatonales al interior de estas piezas. Otros bordes físicos y percibidos compartimentan el espacio urbano de Zaragoza, como las vías e instalaciones del ferrocarril (su efecto se ha atenuado tras la reordenación ferroviaria hecha a raíz de la llegada de la Alta Velocidad en 2003) (Alonso \& Bellet, 2009) y los cursos de agua, especialmente el Ebro y, en algunos sectores, La Huerva y el Canal Imperial de Aragón.

La mayor parte de las actuaciones para la creación de suelo residencial de los últimos treinta ańos se localizan, precisamente, en una orla contigua al espacio urbano consolidado, delimitada por las vías Z-30 y Z-40. Esta franja, que se ensancha hacia el sureste, tiene una superficie que ronda las 4.850 ha, es decir, unas 950 ha mayor que el espacio urbano desarrollado en toda la historia de la ciudad. En esta corona se ubican los grandes barrios sociales (Arcosur, Valdespartera, Parque 
Venecia, Montecanal y Rosales del Canal), así como la mayor parte de las áreas de desarrollo del PGOU 2008 (figura 3).

$\mathrm{Al}$ interior de este anillo se localizan también otros usos de suelo especializados que ocupan superficies considerables, como las dedicadas a centros comerciales (Alcampo, Plaza Imperial y Puerto Venecia) o servicios como los judiciales (Ciudad de la Justicia en el espacio Expo 2008) y universitarios (Campus Río Ebro de la Universidad de Zaragoza).

FIGURA 3 | Usos principales y edificabilidad de las “áreas de desarrollo" del PGOU 2008

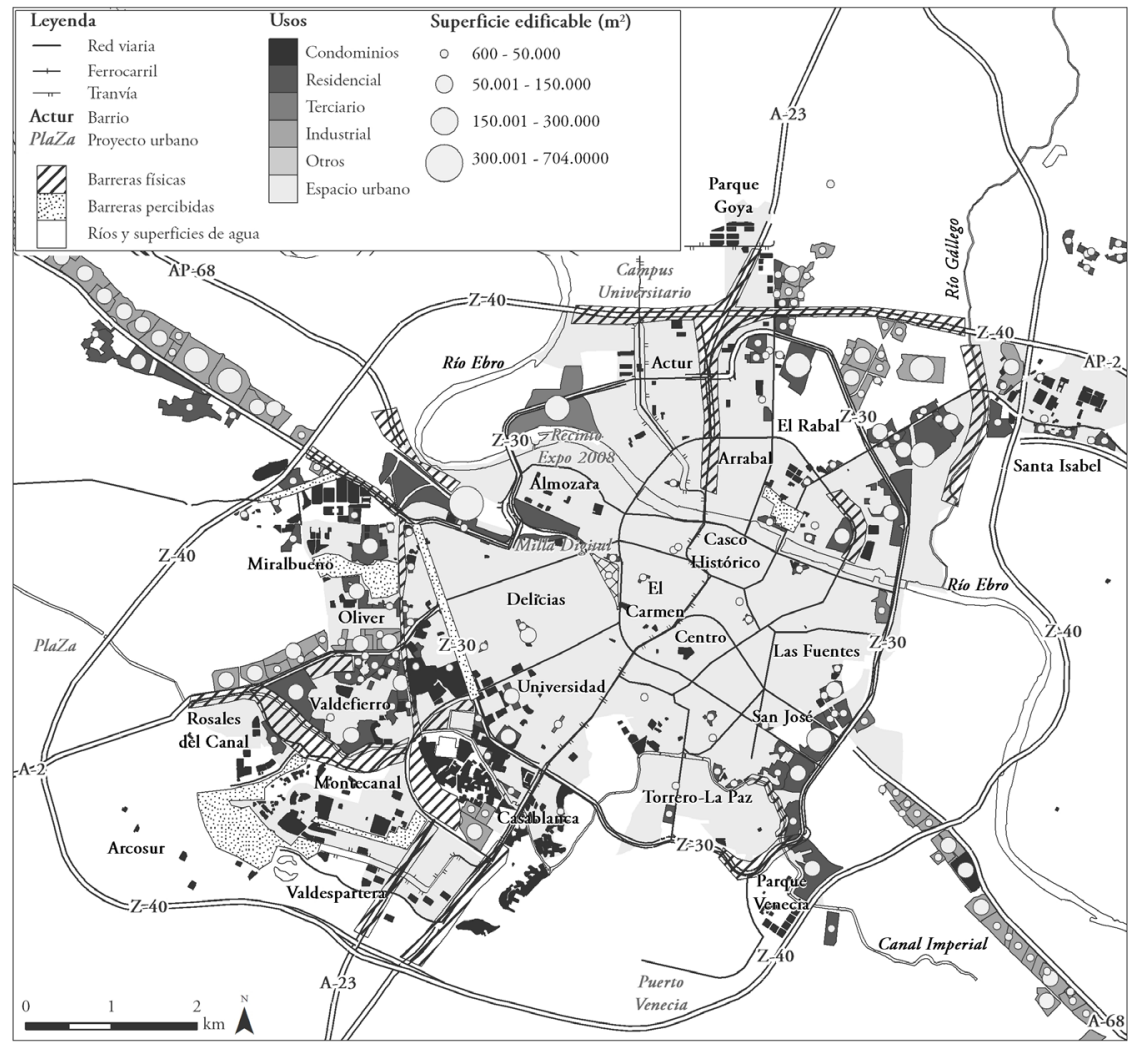

FUENTE SIUA (2OI 5), MINISTERIO DE FOMENTO, IGEAR. ELABORACIÓN PROPIA

La mayor parte del suelo industrial creado en las tres últimas décadas se ubica en una franja adyacente, por el exterior, a la vía Z-40. Algunos polígonos destacan, como se ha señalado, por sus enormes dimensiones, en especial la plataforma logística Plaza, el polígono Empresarium y el Parque Tecnológico del Reciclado. Aún cabría añadir la superficie complementaria que requiere la actividad industrial, especialmente para infraestructuras de transporte (vías auxiliares y accesos).

El segundo nivel de compartimentación se corresponde con una textura de grano más fino, reconocible en los sectores residenciales identificados anteriormente. En 
este caso, las rupturas del espacio urbano se originan por la presencia de parcelas residenciales y espacios libres cercados con vallas y tapias que reducen el espacio público al mínimo, casi exclusivamente a las vías de circulación rodada para acceder a las propiedades.

En los sectores de nuevo desarrollo, la proporción entre la superficie ocupada por la edificación y la superficie total de las parcelas es considerablemente menor que en el tejido histórico, como demuestra el índice de espacio abierto (openness index). Como se observa en la figura 4, los valores más elevados de este índice corresponden al casco histórico y a los barrios tradicionales de la ciudad, incluidos los periféricos situados entre las circunvalaciones Z-30 y Z-40 (Oliver y Valdefierro). En cambio, el espacio urbano de reciente desarrollo tiene valores más bajos, generalmente inferiores a 0,3 (menos del $30 \%$ del suelo está ocupado por edificios). No obstante, en algunos barrios (Valdespartera, Arcosur y Parque Venecia) la proporción de espacio edificado es similar a la de varios sectores del casco histórico (valor del índice entre 0,3 y 0,5).

FIGURA 4 Openness index (índice de espacio abierto), 2015

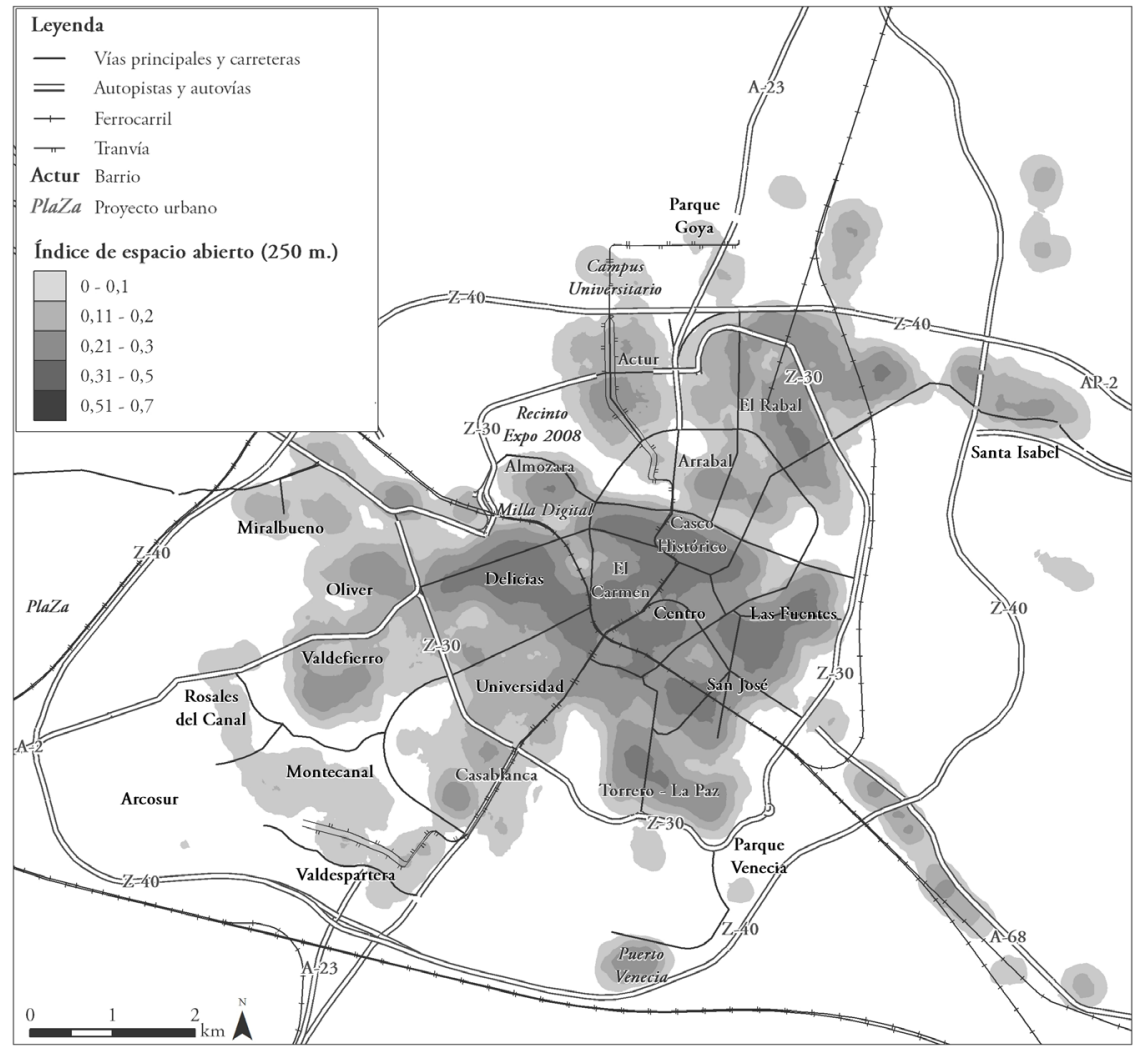

FUENTE ELABORACIÓN PROPIA A PARTIR DE CATASTRO (2OI5), SIU, MINISTERIO DE FOMENTO, IGEAR. 
Estos valores reflejan también la diferente variedad de espacios que componen el tejido urbano tradicional y el nuevo. En lo que se refiere al dominio privado, en el casco histórico y los barrios tradicionales las parcelas están casi totalmente ocupadas por la edificación y patios de luces, a veces muy exiguos. En cambio, en las nuevas áreas urbanizadas, los edificios comparten el suelo con otros espacios, como jardines, zonas de juego, piscinas y porches, especialmente en los condominios.

La diferenciación social cabalga entre ambas escalas: mientras que los nuevos barrios de la periferia son bastante homogéneos en la forma urbana y el estatus socioeconómico de los residentes, en los barrios tradicionales periféricos (Valdefierro, Oliver, Arrabal) el caserío y el estatus socioeconómico de los sectores originales presenta contrastes muy acusados con los sectores nuevos.

\section{Fragmentación urbana, relocalización de la población y prácticas cotidianas}

La considerable ampliación del suelo urbano de Zaragoza durante los tres primeros lustros del siglo xxI, materializada en grandes fragmentos monofuncionales yuxtapuestos al tejido urbano preexistente, ha impulsado la dispersión espacial de la población y de los empleos y, al mismo tiempo, ha hecho que se incremente el grado de compacidad de la población en relación con el espacio urbano.

En efecto, entre 2001 y 2005 la residencia de la población se diseminó ligeramente por el territorio municipal, puesto que la mayor la mayor parte de la población que cambió su residencia se asentó en los márgenes del espacio consolidado. En 2001, la distancia media de la población al centro de la ciudad (Plaza de España) era de 2,6 km, medida en línea recta, que ascendió a 2,8 km en 2011, valor que se mantiene en 2015 . Entre 2001 y 2011 el índice de dispersión $\rho$ registró un aumento leve de la dispersión de la población en relación con el espacio construido, pues su valor pasó de 1,09 a 1,17, pero los efectos de la crisis han revertido la dispersión, pues en 2015 el índice muestra que la compacidad de la población ha crecido $(\rho=0,90)$. La evolución de este indicador revela cierta contención de la dispersión de la población en el último quinquenio y que la velocidad del incremento del espacio urbano es mayor que la de su ocupación por la población.

Las modificaciones de la estructura de la densidad de población entre 2001 y 2014 muestran, en cambio, el desplazamiento de la residencia de la población hacia la periferia, especialmente a la franja entre 4 y $6 \mathrm{~km}$ del centro, aunque este mantiene su densidad en este periodo (figura 5).

En el caso de otras ciudades españolas, Valencia ha consolidado de forma reciente un modelo urbano de mayor complejidad en su periferia urbana inmediata mediante espacios articulados por la red viaria (Salom \& Fajardo, 2017), mientras que Madrid ha pasado de un modelo concentrado en los años sesenta y setenta al crecimiento de su periferia urbana con un modelo basado en la dispersión, la fragmentación y las bajas densidades (García Palomares \& Gutiérrez Puebla, 2007). En cambio, la Región Metropolitana de Barcelona se ha extendido mediante un proceso de densificación, ocupando los espacios intersticiales con una mixtura de usos del suelo que ha permitido la reducción de la fragmentación de los tejidos urbanizados durante los últimos años, y que se espera continúe en el futuro (Marmolejo Duarte \& Stallbohm, 2008; Muñiz \& García-López, 2013). 
FIGURA 5 | Estructura de la densidad de población: coronas en torno al centro urbano $250 \mathrm{~m}$ de radio. 2001-2014

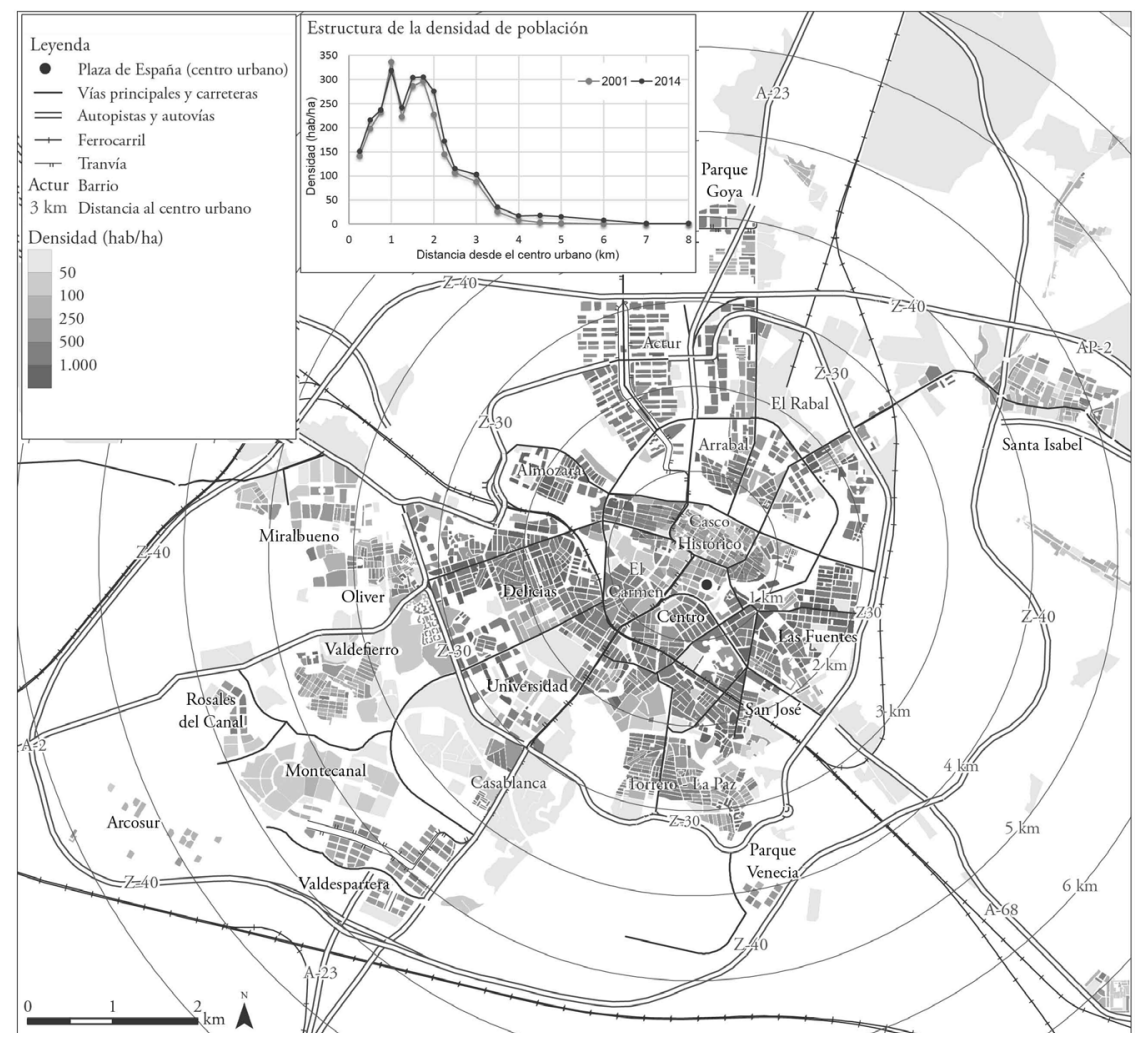

FUENTE ELABORACIÓN PROPIA A PARTIR DE PADRÓN MUNICIPAL DE HABITANTES, AYUNTAMIENTO DE ZARAGOZA, IGEAR. ELABORACIÓN PROPIA

La creación de nuevos barrios muy populosos de viviendas sociales, de calidad razonable y a precios asequibles, en la periferia, como Parque Goya (8.718 habitantes en 2014), Parque Venecia (1.905 habitantes en 2014), Valdespartera (17.122 habitantes en 2014), Rosales del Canal (4.677 habitantes en 2014) y Arcosur (1.638 habitantes en 2014), entre otros, ha impulsado la salida de población joven y adulta del casco urbano, que ha sido sustituida en varios sectores por población inmigrante que encuentra aquí viviendas más baratas.

Este proceso migratorio ha incrementado la segregación residencial y ha significado el envejecimiento de algunas áreas del centro histórico y de los barrios tradicionales (Delicias, Torrero, San José, El Carmen, Las Fuentes, etcétera), aunque este ha sido frenado y revertido por la presencia de inmigrantes. Por una parte, la población extranjera se ha asentado en los sectores más deprimidos y de viviendas más baratas del casco histórico y de las partes más antiguas de los barrios tradicionales; y, por otra, los grupos sociales de mayores ingresos se concentran en determinados lugares de los nuevos desarrollos. Los grupos más jóvenes, generalmente asalariados, se han 
concentrado en los barrios de viviendas sociales (en Valdespartera más del 63\% de su población está comprendida entre los 25 y 45 ańos, y apenas suponen el $7 \%$ de la población total los mayores de 65 años), mientras que las clases medias-altas y las más acomodadas se localizan en lugares más centrales (Plaza de los Sitios, Gran Vía, Sagasta y Constitución) o en residencias unifamiliares (algunos sectores de Universidad y urbanizaciones en los márgenes de Vía Hispanidad y del Canal Imperial).

La presencia de grandes superficies y de centros comerciales periféricos constituye el rasgo más destacable del proceso de renovación de las estructuras comerciales de Zaragoza, iniciado ya en la década de 1970. El PGOU 2008 contempla una previsión de 43 ha de suelo para uso terciario, que se suma a la considerable superficie ya existente de uso comercial, oficinas y otros servicios. En 2009, en el municipio de Zaragoza se asentaban doce centros comerciales que ocupaban 63 ha y sumaban 1.087 tiendas (Arnal, Asín \& Blanco, 2009).

La lógica de la localización periférica de estas actividades, en particular la de los centros comerciales, descansa en su excelente accesibilidad a dos escalas. Por una parte, a escala regional, pues estos centros extienden su influencia no solo a la población del entorno de Zaragoza, sino a otras áreas fuera de los límites de la Comunidad Autónoma; por otra, a escala de la ciudad, las vías de ronda conectan de forma directa las viviendas de los nuevos desarrollos de los márgenes del espacio urbano con las áreas comerciales y de servicios, sobre todo en vehículo privado.

En el mismo sentido, la ocupación del suelo en grandes fragmentos monofuncionales y en condominios vallados reduce la diversidad de actividades debido, entre otras razones, a la ausencia de locales comerciales para las mismas. Así, prácticamente todos los bienes y servicios, incluidos los cotidianos, han de adquirirse en otros lugares más o menos distantes de la residencia, generalmente en los nuevos centros comerciales.

Los contrastes son intensos en las zonas de borde entre estas nuevas áreas y los barrios tradicionales, como sucede en algunos sectores entre Miralbueno y Oliver o el contacto entre Montecanal, Rosales del Canal y Valdespartera. Sin embargo, el contacto de estas piezas con el espacio urbano continuo permite a sus residentes aprovechar los servicios y equipamientos de la ciudad consolidada, lo que genera un sistema de flujos bastante intenso en algunos sectores.

Este hecho distingue la fragmentación con aislamiento y gran autonomía propia de grandes unidades, como en el caso de ciudades norteamericanas (Razin \& Rosentraub, 2000) o los "barrios privados o cerrados" de las urbes latinoamericana (Hidalgo \& Borsdorf, 2005; Janoschka, 2002; Low, 2006; Prévôt-Schapira, 1999), del tipo de fragmentación en grandes piezas bastante homogéneas, pero cuyos límites son permeables. Esta configuración da lugar a un sistema de relaciones socioespaciales más complejo que el de fragmentos más aislados. Así, los vínculos que se establecen desde estas zonas con los barrios del entorno (Casablanca, Valdefierro y Oliver) son relativamente fuertes, pues en los establecimientos de estos barrios se adquieren algunos de los bienes y servicios cotidianos o se utilizan determinados equipamientos (educativos, sociales y de salud). También el centro urbano forma parte de la red de lugares de relación, pues la conexión por transporte público es aceptable y muy buena en los sectores atendidos por la línea 1 del tranvía. 
Finalmente, los centros comerciales periféricos se han convertido también en focos del entramado de lugares de relación al albur de su diversificación funcional (comercio cotidiano y especializado, servicios y actividades recreativas, etcétera). Para los fragmentos aislados, los centros comerciales constituyen una referencia principal. En estos centros confluyen diferentes grupos sociales y étnicos, aunque los efectos de esta coincidencia espacial, en términos de enriquecimiento de las relaciones sociales, puedan ser meramente circunstanciales.

En resumen: la ampliación del espacio urbano con grandes fragmentos monofuncionales y microfragmentados en su interior, ha dado lugar a la emergencia de partes bien diferenciadas del espacio urbano continuo, pero con el que mantiene varios puntos de anclaje.

\section{Conclusiones}

El proceso de desarrollo urbano de Zaragoza en los primeros quince años del siglo XXI responde a formas de intervención en la ciudad propias del sistema económico neoliberal, como su concepción en "planes estratégicos", su ejecución mediante sociedades mixtas con participación pública y privada en los proyectos más emblemáticos o su elevado grado de fragmentación.

Junto a varios rasgos comunes con otras ciudades, las transformaciones urbanas recientes de Zaragoza presentan otros específicos, como el gigantismo y sobredimensionamiento de algunos edificios y proyectos, aspecto que Augé (2001) identifica como una cualidad peculiar de la "sobremodernidad" y, sobre todo, los relativos a los patrones espaciales de la expansión urbana.

En primer lugar, los nuevos desarrollos no han trastocado, sino que han ampliado, el orden espacial radiocéntrico anterior, definido por seis ejes radiales (que enlazan con las carreteras principales), a los que se han añadido, ya en el siglo xxi, segmentos que completan dos vías de circunvalación que canalizan el movimiento circular. Este viario principal ha articulado con el conjunto urbano ciertos sectores del espacio periurbano antes aislados, pero, al mismo tiempo, ha reforzado su condición de fragmentos monofuncionales.

En efecto, el modelo de fragmentación reciente se caracteriza por las rupturas con el espacio urbano consolidado, aunque los parches urbanos no están separados por grandes espacios vacíos, sino solados al espacio preexistente por las nuevas arterias de circulación. Esta configuración tiene sus propias implicaciones socioespaciales a escala metropolitana, diferentes de la fragmentación mediante bolsas de suelo urbano separadas unas de otras.

A mesoescala, los nuevos desarrollos urbanos no aparecen desconectados ni aislados del tejido urbano continuo, con el que forman un complejo sistema de relaciones funcionales y sociales. En todo caso, se necesitan estudios detallados para comprobar los efectos sociales, económicos y demográficos de la promoción de barrios enteros de viviendas sociales y la agrupación de condominios y residencias familiares valladas en otros sectores. Esta separación de los tipos de residencia incrementa la segregación socioespacial por grupos económicos y por edades, al mismo 
tiempo que preserva el valor de las propiedades, pues el suelo disponible en estos sectores ya ha sido ocupado por grupos sociales bastante homogéneos.

La expansión periférica del espacio residencial en grandes manchas con densidades medias y bajas ha fraguado un modelo funcional policéntrico basado en el uso del automóvil privado. A diferencia del policentrismo jerarquizado de los centros o calles comerciales tradicionales de los barrios, que proporcionan bienes cotidianos en la proximidad de los domicilios, los nuevos centros especializados o generalistas ejercen atracción para todo tipo de bienes y en todo el espacio urbano y metropolitano, por lo que genera más desplazamientos con origen aleatorio.

En este sentido, la ciudad real se aparta del modelo territorial policéntrico, equilibrado y sostenible, propugnado en la planificación, lo que refleja ciertas debilidades del modo de gobernanza urbana, es decir, en cómo y con qué fundamento se tomaron decisiones para construir miles de viviendas, edificios para equipamientos y otras actividades y acondicionar suelo industrial, en Zaragoza y municipios de su entorno, cuyas dotaciones rebasan cualquier previsión prudente o la consideración de otras estrategias. También es muestra de las insuficiencias de los instrumentos y normas de planeamiento urbano, así como de la incapacidad de la administración local y autonómica para controlar los procesos de urbanización del territorio, bien por errores cometidos en la planificación, por dejación de funciones o por falta de medios de vigilancia y gestión.

Como conclusión final, se puede afirmar que el rasgo específico de la fragmentación producida en la ciudad de Zaragoza en los quince primeros ańos del siglo XXI se encuentra en que los nuevos fragmentos se hallan soldados por puntos estratégicos al espacio urbano continuo preexistente. Este hecho ha permitido la formación de un sistema de flujos en varios sectores de la interfaz de ambos espacios, no tan continuos ni complejos como los de los barrios tradicionales, pero sí diferentes del modelo disperso y aislado de grandes unidades casi autónomas. Dicho de otro modo: la fragmentación reciente de Zaragoza se caracteriza por la existencia de partes diferenciadas y microfragmentadas, pero con conexiones espaciales y funcionales con el tejido urbano anterior.

\section{Agradecimientos}

Este artículo se ha realizado con el apoyo del proyecto de investigación "Indicadores multiescalares y herramientas cartográficas para el análisis de la vulnerabilidad socioeconómica y residencial en áreas urbanas. Aplicación al caso de Zaragoza” (proyecto no cso2016-74888-c4-3-r), del Programa Estatal de Investigación, Desarrollo e Innovación Orientada a los Retos de la Sociedad, del Ministerio de Economía, Industria y Competitividad del Gobierno de España; y del Gobierno de Aragón con la financiación del Fondo Social Europeo. 


\section{Referencias bibliográficas}

Alonso, M .P. \& Bellet, C. (2009). El tren de alta velocidad y el proyecto urbano. Un nuevo ferrocarril para la Zaragoza del tercer milenio. Scripta Nova. Revista Electrónica de Geografia y Ciencias Sociales, XIII, 281. http://www.ub.edu/geocrit/sn/sn-281.htm

Angel, S., Parent, J. \& Civco, D. (2007). Urban sprawl metrics: an analysis of global urban expansion using GIs. Tampa 2007 ASPRS Annual Conference Proceedings (p. 12). Tampa, Florida: s.n. http://www.asprs.org/a/publications/proceedings/tampa2007/0003.pdf

Arnal, J. C., Asín, F. \& Blanco, J. (eds.). (2009). Atlas de la ciudad de Zaragoza. 2009. Zaragoza: Ayuntamiento de Zaragoza.

Artigues, A. A., Bauzà, A., Blázquez, M., González, J. M., Murray, I. \& Rullán, O. (eds.). (2007). Los procesos urbanos postfordistas. Actas del VIII Coloquio y Jornadas de Campo de Geografía. S.l.: Universitat de les Illes Balears y Asociación de Geógrafos Españoles.

Augé, M. (2001). Los "no lugares": espacios del anonimato. Una antropología de la sobremodernidad. Barcelona: Gedisa.

Ayuntamiento de Zaragoza (s/f). Renovación del Plan Integral del Casco Histórico de Zaragoza, 2005-2012. Zaragoza: Ayuntamiento de Zaragoza. https://www.zaragoza.es/ciudad/ urbanismo/planeamiento/enlace/urbanismo/pich.htm

Ayuntamiento de Zaragoza (1992). El plan de 1986. Una visión retrospectiva. S.l. Zaragoza: Ayuntamiento de Zaragoza.

Ayuntamiento de Zaragoza (2008). Plan general de ordenación urbana. Memoria expositiva. 2008. S.l.: s.n. http://www.zaragoza.es/ciudad/urbanismo/planeamiento/pgouz/memoria.htm

Batty, M., Chin, N. \& Besussi, E. (2002). State of the art review of urban sprawl impacts and measurement techniques. Deliverable Report. SCATTER Sprawling Cities and Transport: from Evaluation to Recommendations. http://www.casa.ucl.ac.uk/scatter/download/Scatter_D1.pdf

Bellet, C. \& Alonso, P. (2016). Proyectos urbanos incompletos. Vacíos urbanos en la Zaragoza post-AVE. Boletín de la Asociación de Geógrafos Españoles, 70, 285-304. https://doi. org/10.21138/bage. 2172

Bertaud, A. (2001). Metropolis: A measure of the spatial organization of 7 large cities. S.l.: s.n. http://alainbertaud.com/wp-content/uploads/2013/06/AB_Metropolis_Spatial_ Organization.pdf

Biel, M. P. (2004). Zaragoza y la industrialización: la arquitectura industrial en la capital aragonesa entre 1875-1936. Zaragoza: Institución Fernando el Católico.

Borsdorf, A. \& Hidalgo, R. (2010). From polarization to fragmentation. Recent changes in Latin American urbanization. En P. V. Lindert \& O. Verkoren (eds.), Decentralized development in Latin America: Experiences in local governance and local development (pp. 23-34). Dordrecht, Heidelberg, Londres y Nueva York: Springer.

Burriel, E. L. (2015). Empty urbanism: the bursting of the Spanish housing bubble. Urban Research \& Practice, 9(2), 158-180. https://doi.org/10.1080/17535069.2015.1110196

Calderón, B. (2012). Del centralismo a la hipertrofia normativa regional: 1990-2010. Nuevas leyes para ordenar la ciudad. En M. Valezuela (ed.), El impacto del modelo autonómico en las ciudades españolas. Una aproximación interdisciplinar (pp. 57-96). Madrid: Ediciones Universidad Autónoma de Madrid.

Capron, G. \& González Arellano, S. (2006). Las escalas de la segregación y de la fragmentación urbana. Trace. Travaux et Recherches dans les Amériques du Centre, 49, pp. 65-75. http:// www.redalyc.org/articulo.oa?id=423839505006 
Castells, M. (1991). El auge de la ciudad dual: teoría social y tendencias sociales. Alfoz: Madrid, territorio, economía y sociedad, 80, 89-103.

Calvo-Palacios, J. L., Pueyo-Campos, Á. \& Zúñiga-Antón, M. (2011). La ciudad de Zaragoza en un escenario de crisis: diagnóstico y propuestas territoriales para nuevos paradigmas urbanos. Geographicalia, 59-60, 47-59. https:/papiro.unizar.es/ojs/index.php/ geographicalia/article/view/821/0

Chin, N. (2002). Unearthing the roots of urban sprawl: a critical analysis of form, function and methodology. Working Paper Series, 47. Londres: Centre for Advanced Spatial Analysis. http://discovery.ucl.ac.uk/249/1/Paper47.pdf

Deffner, V. \& Hoerning, J. (2011). Fragmentation as a threat to social cohesion? A conceptual review and an empirical approach to Brazilian cities. The struggle to belong. Dealing with diversity in 21st century urban settings. International RC21 Conference (p. 15). Amsterdam: s.n. http://www.rc21.org/conferences/amsterdam2011/edocs2/Session\%20 15/15-1-Deffner.pdf

De Mattos, C. (2010). Globalización y metamorfosis metropolitana en América Latina. De la ciudad a lo urbano generalizado. Revista de Geografia Norte Grande, 47, 81-104. http:// dx.doi.org/10.4067/S0718-34022010000300005

De Miguel González, R. (2015). Transformación urbana y procesos territoriales recientes en Zaragoza y su espacio metropolitano. Estudios Geográficos, 76(278), 63-106. http:// dx.doi.org/10.3989/estgeogr.201503

Del Romero, L. (2010). Dos décadas de urbanismo-espectáculo en España: los grandes eventos como motor del cambio urbano. Boletín de la Asociación de Geógrafos Españoles, 53, 309-327.

Dirección General del Catastro (2011). Fichero informático de remisión de catastro (bienes inmuebles urbanos, rústicos y de características especiales). S.l.: s.n. http://www.catastro.minhap.es/ documentos/formatos_intercambio/catastro_fin_cat_2006.pdf

Duranton, G. \& Puga, D. (2004). From sectoral to functional urban specialization. CEPR Discussion Paper, 2971. Londres: Centre for Economic Policy Research (CEPR). http://diegopuga. org/papers/sec2func.pdf

Ebrópolis (2006). Plan estratégico de Zaragoza y su entorno. Zaragoza: Ebrópolis.

Ebrópolis (2011). Marco estratégico. Zaragoza 2020. Zaragoza: Ebrópolis.

Escolano, S. (2005). Algunos rasgos geográficos del reciente proceso de formación del área metropolitana de Zaragoza. Territorio y Desarrollo Local, 2, Monográfico 1, 27-40. http://bit.ly/2wDc3M2

Escolano, S. \& Salvador, J. A. (2013). Conocimiento y ciudades: la experiencia de Milla Digital de Zaragoza (España). En M. Valenzuela (ed.), Las ciudades españolas en la encrucijada: entre el "boom" inmobiliario y la crisis económica (pp. 497-538). Madrid: Real Sociedad Geográfica y Asociación de Geógrafos Españoles. http://urbspain.wordpress.com

Faus, C. (1978). El ferrocarril y la evolución urbana en Zaragoza. Geographicalia, 2, 83-114. https://dialnet.unirioja.es/servlet/articulo?codigo $=59685$

Fernández-Tabales, A. \& Cruz Mazo, E. (2013). Análisis territorial del crecimiento y la crisis del sector de la construcción en España y la Comunidad Autónoma de Andalucía. EURE, 39(116), 5-37. http://dx.doi.org/10.4067/S0250-71612013000100001

Florida, R. L. (2003). The rise of the creative class: and how it's transforming work, leisure, community and everyday life. North Melbourne, Victoria: Pluto Press. 
Forcadell-Álvarez, C. (2004). La pelea por la memoria y el control del pasado en la Zaragoza de 1908. En vv.AA. (eds.), La modernidad y la exposición hispano-francesa de Zaragoza de 1908 (pp. 13-23). Zaragoza: Universidad de Zaragoza y cAI.

Gaggiotti, H., Kostera, M., Bresler, R. \& San Román, B. (2015). El nomadismo y el movimiento como epistemología del mundo contemporáneo. Scripta Nova: Revista electrónica de geografia y ciencias sociales, XIX, 5101. http://www.ub.edu/geocrit/sn/sn-510-1.pdf

García-Lasaosa, J. (1979). Desarrollo urbanistico de Zaragoza (1885-1908). Zaragoza: Institución Fernando El Católico.

García Palomares, J. C. \& Gutiérrez Puebla, J. (2007). La ciudad dispersa: cambios recientes en los espacios residenciales de la Comunidad de Madrid. Anales de Geografia de la Universidad Complutense, 27(1), 4567. http://revistas.ucm.es/index.php/AGUC/article/ view/AGUC0707110045A

Gómez, C. \& Sanaú, J. (eds.). (2009). La Exposición Internacional Zaragoza 2008. Zaragoza: CESA, Consejo Económico y Social de Aragón.

Gurovich, A. (2013). El desarrollo del paradigma neoliberal en la experiencia urbanística chilena. En E. López-Morales, C. Arriagada, P. Jirón \& H. Eliash (eds.), Chile urbano hacia el siglo XXI. Investigaciones y reflexiones de política urbana desde la Universidad de Chile (pp. 52-57). Santiago de Chile: Editorial Universitaria.

Harrison, P. F. (2013). Fragmentation and globalisation as the new meta-narrative. P. En Harrison, M. Huchzermeyer \& M.Mayekiso (eds.), Confronting fragmentation: housing and urban development in a democratising society (pp. 13-25). Ciudad del Cabo: University of Cape Town.

Harrison, P., Huchzermeyer, M., Mayekiso, M. \& Sholto-Douglas, S. (2013). Confronting fragmentation: housing and urban development in a democratising society. S.l.: s.n. Consultado el 2 de octubre de 2015. En http://alltitles.ebrary.com/Doc?id=10953398

Harvey, D. (1998). La condición de la posmodernidad: investigación sobre los origenes del cambio cultural. Buenos Aires: Amorrortu. (Ed. original, 1989: The condition of postmodernity. An enquiry into the origins of cultural change. Oxford: Blackwell).

Hidalgo, R. \& Borsdorf, A. (2005). Barrios cerrados y fragmentación urbana en América Latina: estudio de las transformaciones socioespaciales en Santiago de Chile (19902000). En R. Hidalgo, R. Trumper \& A. Borsdorf (eds.), Transformaciones urbanas y procesos territoriales. Lecturas del nuevo dibujo de la ciudad latinoamericana (pp. 105-122). Santiago: Academia de Ciencias Austriaca y Okanagan University College.

Hidalgo, R. \& Janoschka, M. (eds.). (2014). La ciudad neoliberal. Gentrificación y exclusión en Santiago de Chile, Buenos Aires, Ciudad de México y Madrid. Serie Geolibros, 19. Santiago de Chile: Pontificia Universidad Católica de Chile / Universidad Autónoma de Madrid.

Inostroza, L., Baur, R. \& Csaplovics, E. (2013). Urban sprawl and fragmentation in Latin America: A dynamic quantification and characterization of spatial patterns. Journal of Environmental Management, 115, 8797. https://doi.org/10.1016/j.jenvman.2012.11.007

Janoschka, M. (2002). El nuevo modelo delaciudad latinoamericana: fragmentacióny privatización. EURE, 28(85), 11-29. http://dx.doi.org/10.4067/S0250-71612002008500002

Jiménez-Zarzo, F., Martínez-Buenaga, I., Martínez-Prades, J. A. \& Martínez-Verón, J. (2004). El verano más hermoso. En vV.AA. (eds.), La modernidad y la exposición hispano-francesa de Zaragoza de 1908 (pp. 2580). Zaragoza: Universidad de Zaragoza y CAI. 
Jirón, P. \& Mansilla, P. (2014). Las consecuencias del urbanismo fragmentador en la vida cotidiana de habitantes de la ciudad de Santiago de Chile. EURE, 4O(121), pp. 5-28. http://dx.doi.org/10.4067/S0250-71612014000300001

López-Escolano, C., Pueyo-Campos, Á., Valdivielso-Pardos, S. \& Hernández-Navarro, M. L. (2015). Transformaciones espaciales y de actividad frente a las dinámicas globales en el entorno metropolitano de Zaragoza. En A. Espinosa Seguí \& F. J. Antón Burgos (eds.), El papel de los servicios en la construcción del territorio: redes y actores (pp. 285302). Alicante: Asociación de Geógrafos Españoles.

Low, M. \& Barnett, C. (2000). After globalisation. Environment and Plannig D; Society and Space, 18(1), 5361. http://dx.doi.org/10.1068/d8s

Low, S. (2006). Towards a theory of urban fragmentation: A cross-cultural analysis of fear, privatization, and the state. CyberGeo, Vol. 2006, 134. http://cybergeo.revues. org/3207?lang=es

Lussault, M. (2017). Hyper-lieux. Les nouvelles géographies de la mondialisation. París: Éditions du Seuil, Col. La couleur des idées.

Marcuse, P. (2009). 'Dual city': a muddy metaphor for a quartered city. International Journal of Urban and Regional Research, 13(4), 697708. http://dx.doi.org/10.1111/j.1468-2427. 1989.tb00142.x

Marcuse, P. \& Van Kempen, R. (eds.). (2000). Globalizing cities: a new spatial order? Malden, MA / Oxford, uk / Carlton, Victoria, Australia: Blackwell Publishing.

Marín, C. E. (2009). Caracterización de la fragmentación urbana reciente de la ciudad de Zaragoza. Tesis para optar al grado de Máster. Zaragoza: Universidad de Zaragoza.

Marmolejo Duarte, C. \& Stallbohm, M. (2008). En contra de la ciudad fragmentada: ¿̧hacia un cambio de paradigma urbanístico en la región metropolitana de Barcelona? Scripta Nova: Revista electrónica de geografía y ciencias sociales, número extra 12, 270. http://www. ub.edu/geocrit/sn/sn-270/sn-270-65.htm

May, F. (1997). From territorial production systems to metropolitanization: ten years of research in France. En F. Moulaert \& A. J. Scott (eds.), Cities, Enterprises and Society on the eve of the 21st Century (pp. 57-77). London and Washington, D.C.: Pinter.

Michelutti, E. (2010). An analytical framework for urban fragmentation analysis in the Global South city. Questioning urban planning practices through an institutional approach. XIth N-AERUS Conference. Bruselas: s.n. http://n-aerus.net/web/sat/workshops/2010/ Brussels_2010.htm

Ministerio de Fomento (s/f). Sistema de Información Urbana (sıU). Consultado 19 de octubre de 2015. En http://www.fomento.gob.es/MFOM/LANG_CASTELLANO/ DIRECCIONES_GENERALES/ARQ_VIVIENDA/SUELO_Y_POLITICAS/SIU/

Ministerio de Fomento (2010). Atlas Digital de las Áreas Urbanas de España. http://siu.vivienda. es/portal/index.php?option=com_content\&view=category\&layout=blog\&id=19\&Item id $=73$ \&lang $=e s$

Moulaert, F., Scott, A.J. \& Farcy, H. (1997). Producer services and the formation of urban space. En F. Moulaert \& A. J. Scott (eds.), Cities, enterprises and society on the eve of the 21st century (pp. 97-112). Londres y Washington: Pinter.

Muñiz, I. \& García-López, M.A. (2013). Anatomía de la dispersión urbana de Barcelona. EURE, 39(116), 189219. http://dx.doi.org/10.4067/S0250-71612013000100008 
Navez-Bouchanine, F. (Ed.). (2002a). La fragmentation en question: des villes entre fragmentation spatial et fragmentation sociale? París: L'Harmattan.

Navez-Bouchanine, F. (2002b). Emergence d'une notion: quelques repéres historiques. En F. Navez-Bouchanine (ed.), La fragmentation en question: des villes entre fragmentation spatial et fragmentation sociale? (pp. 1944). París: s.n.

Nel.lo, O. \& Donat, C. (2014). Los efectos territoriales de la crisis económica en la región metropolitana de Barcelona. En J. M., Albertos Puebla \& J. L., Sánchez Hernández (coords.), Geografía de la crisis económica en España (pp. 565-609). Valencia: Servei de Publicacions de la Universitat de València.

Pinson, G. \& Morel Journel, C. (2016). The neoliberal city-theory, evidence, debates. Territory, Politics, Governance, 4(2), 137153. http://dx.doi.org/10.1080/21622671.2016.1166982

Prévôt-Schapira, M. F. (1999). Amérique Latine: la ville fragmentée. Esprit, 258(11), 128-144.

Razin, E. \& Rosentraub, M. (2000). Are fragmentation and sprawl interlinked? North American evidence. Urban Affairs Review, 35(6), 821836. http://dx.doi.org/10.1177/107808700 22184697

Reis, J. P., Silva, E. A. \& Pinho, P. (2016). Spatial metrics to study urban patterns in growing and shrinking cities. Urban Geography, 37(2), pp. 246-271. http://dx.doi.org/10.1080/027 23638.2015.1096118

Retaillé, D. (2009). Malaise dans la géographie, l'espace est mobile. En M. Vanier (dir.), Territoires, territorialité, territorialisation (pp. 97114). Rennes: Presses Universitaires de Rennes,.

Salom Carrasco, J. \& Pitarch Garrido, M. D. (2014). El Área Metropolitana de Valencia en la crisis. En J. M. Albertos Puebla \& J. L. Sánchez Hernández (coords.), Geografía de la crisis económica en España (pp. 539564). Valencia: Servei de Publicacions de la Universitat de València.

Salom, J. \& Fajardo, F. (2017). Cambios recientes en la estructura territorial sociodemográfica del área metropolitana de Valencia (2001-2011). Boletín de la Asociación de Geógrafos Españoles, 73, 123147. http://roderic.uv.es/handle/10550/47995

Sapena Moll, M. \& Ruiz Fernández, L. Á. (2015). Descripción y cálculo de índices de fragmentación urbana: herramienta IndiFrag. Revista de Teledetección, 43, 7790. http:// dx.doi.org/10.4995/raet.2015.3476

Sassen, S. (1991). The global city: New York, London, Tokyo. Princeton, N.J.: Princeton University Press.

Schneider, A. \& Woodcock, C. E. (2008). Compact, dispersed, fragmented, extensive? A comparison of urban growth in twenty-five global cities using remotely sensed data, pattern metrics and census information. Urban Studies, 45(3), 659692. http:// landcoverchange.com/wp-content/uploads/2014/09/schneider_woodcock_2008.pdf

Schulz-Dornburg, J. \& Argullol, R. (2012). Ruinas modernas, una topografía de lucro (3 $\left.3^{\mathrm{a}} \mathrm{ed}.\right)$. Barcelona: Àmbit. Palabra y paisaje.

Torrens, P. M. (2008). A toolkit for measuring sprawl. Applied Spatial Analysis and Policy, 1(1), 536. http://dx.doi.org/10.1007/s12061-008-9000-x

Valdés, E. (2007). Fragmentación y segregación urbana. Aportes teóricos para el análisis de casos en la ciudad de Córdoba. Alfilo, revista electrónica, 18, 115. http://www.ffyh.unc.edu.ar/ alfilo/anteriores/alfilo-18/pdf/valdes.pdf

Vives, S. \& Rullan, O. (2014). La apropiación de las rentas del suelo en la ciudad neoliberal española. Boletín de la Asociación de Geógrafos Españoles, 65, 387408. http://www.agegeografia.es/ojs/index.php/bage/article/view/1758 